\title{
A Clinical Study of Intestinal Stomas in Emergency Laparotomies
}

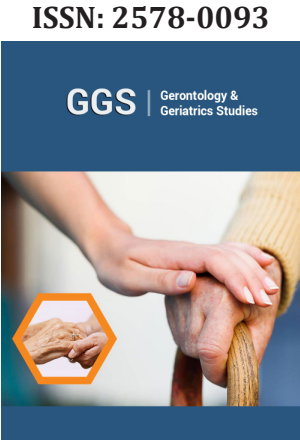

*Corresponding author: Rovena Bode, Department of Surgery, Albania

Submission: 海 August 02, 2019

Published: 海August 21, 2019

Volume 4 - Issue 5

How to cite this article: Rovena Bode, Virna Z, Lorenc B, Hysni D. A Clinical Study of Intestinal Stomas in Emergency Laparotomies. Gerontol \& Geriatric stud.4(5). GGS.000599.2019.

DOI: 10.31031/GGS.2019.04.000599

Copyright@ Rovena B, This article is distributed under the terms of the Creative Commons Attribution 4.0 International License, which permits unrestricted use and redistribution provided that the original author and source are credited.

\author{
Rovena Bode ${ }^{1 *}$, Virna Zyka ${ }^{2}$, Lorenc Bode ${ }^{2}$ and Hysni Dede ${ }^{2}$ \\ ${ }^{1}$ Department of Surgery, Albania \\ ${ }^{2}$ Faculty of Medicine, Albania
}

\begin{abstract}
Background: Intestinal stomas are used to divert the fecal stream away from distal bowel in order to allow a distal anastomosis to heal as well as to relieve obstruction in emergency situation. The aim of the present study was to identify indications for emergency laparotomy, commonly performed intestinal stomas and to study complications related to it.
\end{abstract}

Methods: This is a retrospective study and was carried out in the surgical unit of Mother Teresa University Hospital Center, from January 2017 to August 2018. All patients were admitted through emergency and underwent surgery for various reasons and were followed up to note any complication which resulted in the creation of intestinal stomas, and who fit in to inclusion criteria.

Results: The most common indication for stoma formation was colorectal carcinoma $(\mathrm{n}=77)$ followed by sigmoid volvulus $(n=16)$, perforated sigmoid diverticula $(n=12)$, recto-sigmoid perforation by corpus alienum $(n=6)$. A total of 106 patients underwent colostomy formation, of which 85 were end colostomy and 21 were Baguette colostomy. Thirty-one (31) patients underwent ileostomy formation, of which 9 were loop ileostomy and 10 were temporary end ileostomy, one was double barrel ileostomy. Nine (9) cases were treated with jejunostomy and 5 cases with duodenostomy.

Conclusion: Fecal/intestinal diversion remains an effective option to treat a variety of gastrointestinal and abdominal conditions. Stoma formation is the best minimum surgical procedure to save the life in emergency intestinal surgery for obstructive cancer, inflammatory colic disease, anastomotic leaks with low mortality.

Keywords: Intestinal stoma; Fecal diversion; Emergency surgery; DCS (damage control surgery)

\section{Introduction}

The word "Stoma" comes from the Greek word meaning mouth or opening [1]. An intestinal stoma is an opening of the intestine on anterior abdominal wall made surgically [2]. Stomas are used to divert the fecal stream away from distal bowel in order to allow a distal anastomosis to heal as well as to relieve obstruction in emergency. It may be temporary or permanent; depending on their role [3]. The formation of an intestinal stoma is one of the most frequent operations in emergency gastrointestinal surgery [4]. Despite the new operative techniques and a more restrictive use, the stoma formation remains the best emergency necessary surgical procedure, which results in dramatic improvement in the patient's condition [5]. Though a lifesaving procedure, it may result in significant number of complications. Complications are divided into early complications and late complications. Littre of Paris was the first to make a ventral colostomy in 1710 for a baby with imperforate anus [6]. An ileostomy was first advocated in ulcerative colitis in 1912 but was not widely used until Brooke demonstrated his everted ileostomy in 1952 [7]. Various Indications for which intestinal stomas are formed: ulcerative colitis, bowel obstruction, cancer of colon \& rectum, Crohn's disease, congenital bowel defects, uncontrolled bleeding from large intestine, injury to the intestinal tract, inflammatory bowel disease, ischemic bowel disease, carcinoma urinary bladder and spinal cord injury [8] (up to 30 days after operation) and late complications (more than 30 days after operation). Stoma, though it is a lifesaving procedure, it carries significant number of complications. Despite extensive surgical expertise, complications after stoma creation still occur and often cause social isolation and a significant reduction in the quality of life. The aim of our study is to evaluate the indications and outcome of small and large bowel stomas made during emergency intestinal surgery (Figure 1). 


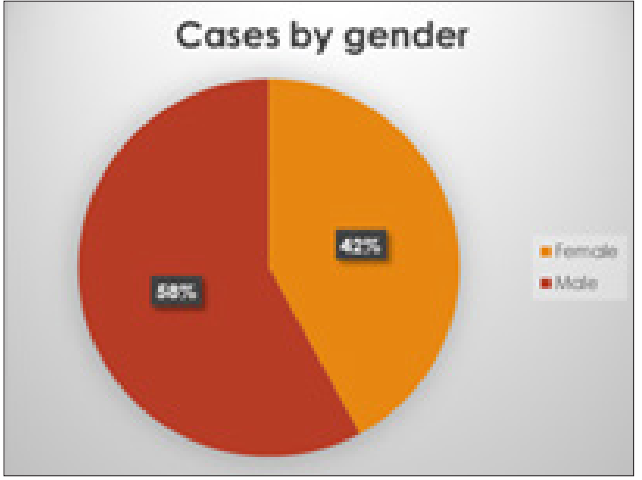

Figure 1: There were a total of 156 patients, 92 male and 64 female patients.

\section{Methodology}

A. This is a retrospective study and was carried out in the surgical unit of Mother Teresa University Hospital Center, from January 2017 to August 2018. All patients were admitted through emergency and underwent surgery for various reasons and were followed up to note any complication which resulted in the creation of intestinal stomas, and who fit in to inclusion criteria. Data was collected by meticulous history taking including age, gender, indication, type of stoma, type of surgery, careful clinical examination, appropriate operative findings and follow up of the cases.

B. Patients who underwent emergency exploratory laparotomy for intestinal surgery and managed either by stoma, covering stoma, exteriorization of perforation or both ends after resection were included in the study (Patients undergoing stoma construction as indication for gynecological disorders were included also). Patients received through emergency were optimized and then underwent exploratory laparotomy.

C. All patients less than 14 years, patients with urinary diversion procedures which involve creation of intestinal stomas and patients with physiological and biochemical complications were excluded from the study.

\section{Results}

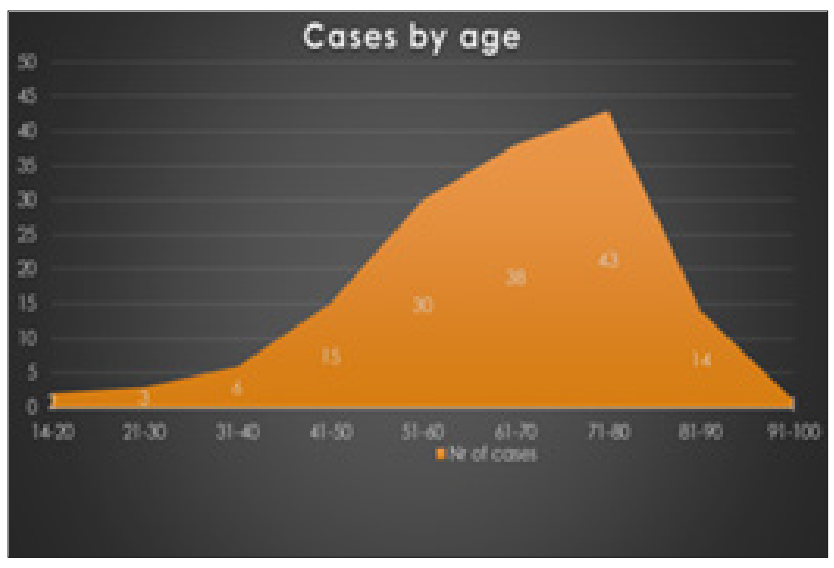

Figure 2: Age distribution.
Their mean age was 64.3 (range 18-92) years. Mean (SD): 64,3 \pm 14.6 years. Maximum number of patients were in the group of 61 80 years. ( $n=81$ out of 156 ), (Figure 2). The most common stoma created was colostomy $(n=106$ of total 156). The indications for performing the emergency laparotomy were: Intestinal occlusion in 84 patients or $53 \%$ of total patients, acute abdomen in 52 patients or $33 \%$, vascular pathology producing bowel ischemia in 13 patients or $8 \%$, entry of foreign objects and penetrating sphincter injuries in 4 patients or $3 \%$. Digestive bleeding was present in 5 patients or $5 \%$ of cases.

The most common indication for stoma formation was colorectal carcinoma $(n=77)$ followed by sigmoid volvulus $(n=16)$, perforated sigmoid diverticula $(n=12)$, recto-sigmoid perforation by corpus alienum $(n=6)$.

Faecal fistula post intestinal surgery was treated with stoma in 8pts, intestinal thrombosis $(\mathrm{n}=8)$, morbus Crohn and ulcerative colitis were treated by stoma in 3 cases, peritoneal carcinomatosis was present in 6 cases, gynecologic infiltrating cancer was present in 3 cases. Sfincter injury by trauma was treated by ostomy also in 4 patients. Carcinoma include: Rectosigmoid locations in $42 \%$ of cases, followed by left colic locations in $10 \%$ of cases, right locations in $1.4 \%$ and peritoneal carcinomatosis in $4 \%$ of cases. Inflammatory pathology of colon was represented by: sigmoid volvulus in $11 \%$ of cases, inflammatory diverticula in $7 \%$ of cases, sigmoid perforation during endoscopy/ surgery/anastomotic/c. alien in 23\% altogether with toxic megacolon and Crohn disease. Other indications were intestinal thrombosis in 5.6\%, gynecological disease in $2.1 \%$ and coloanal injuries in obstetrics, abuse or objects or Fournier in 3\% (Table 1).

Table 1: Intraoperative findings.

\begin{tabular}{|c|c|c|}
\hline Intraoperative Findings & $\mathrm{Nr}$ & $\%$ \\
\hline 1.Rectosigmoid carcinoma & 62 & 42 \\
\hline 2.Left colic flexure cancer & 15 & 10 \\
\hline 3.Perforated sigmoid diverticula & 12 & 7 \\
\hline 4.Sigmoid volvulus & 16 & 11 \\
\hline 5. Sigmoid perforation by corpus alien & 6 & 4 \\
\hline 6.Colon perforation during endoscopy & 1 & 0.7 \\
\hline 7.Colic fistula & 8 & 5.6 \\
\hline 8.Toxic Megacolon & 2 & 1,2 \\
\hline 9.Morbus Crohn & 1 & 0.7 \\
\hline 10.Intestinal thrombosis & 8 & 5.6 \\
\hline 11.Acute Appendicitis & 2 & 1.4 \\
\hline 12. Peritoneal carcinomatosis & 6 & 4 \\
\hline 13. Acute pancreatitis & 1 & 0.7 \\
\hline 14. Duodenal fistula & 4 & 3 \\
\hline 15.infiltrative prostate cancer & 1 & 0.7 \\
\hline 16.Rectal stump necrosis & 1 & 0.7 \\
\hline 17. Right colon cancer & 2 & 1.4 \\
\hline 18. Rectal infiltration from ovarian cancer & 2 & 1.4 \\
\hline 19. Sfincter injury from obstetrical/or not, trauma & 4 & 3 \\
\hline
\end{tabular}


A total of 106 patients underwent colostomy formation, of which 85 were end colostomy and 21 were Baguette colostomy (Table 2). 31 patients underwent ileostomy formation, of which 9 were loop ileostomy and 10 were temporary end ileostomy, one was double barrel ileostomy, 9 cases were treated with jejunostomy, 5 cases with duodenostomy. The most used form of ileostomy constructed was end ileostomy, followed by loop ileostomy and ileostomy with mucous fistula. Ileostomy was preferred mainly for obstructing colorectal cancer with diastatic caecal perforation.

Table 2: Type of stoma constructed.

\begin{tabular}{|c|c|c|}
\hline Types of Stoma & $\mathrm{Nr}$ & $\%$ \\
\hline Loop ileostomy & 9 & 6 \\
\hline End ileostomy & 12 & 7 \\
\hline Double barrel ileostomy & 2 & 0.7 \\
\hline Ileostomy with mucous fistula & 8 & 5.4 \\
\hline End colostomy & 85 & 54 \\
\hline Baguette colostomy & 20 & 13.5 \\
\hline Double barrel colostomy & 1 & 0.7 \\
\hline Jejunostomy & 9 & 6 \\
\hline Duodenostomy & 5 & 3 \\
\hline Gastrostomy & 1 & 0.7 \\
\hline Cholecystostomy & 3 & 2 \\
\hline Ureterostomy & 1 & 0.7 \\
\hline Total & 156 & 100 \\
\hline
\end{tabular}

Table 3:

\begin{tabular}{|c|c|c|c|c|c|}
\hline Ileostomy Indications & $\begin{array}{l}\text { Loop } \\
\text { Ileostomy }\end{array}$ & End Ileostomy & $\begin{array}{l}\text { Double Barrel } \\
\text { Ileostomy }\end{array}$ & $\begin{array}{l}\text { Ileostomy, Mucous } \\
\text { Fistula }\end{array}$ & Total \\
\hline $\begin{array}{l}\text { Obstructive recto/sigmoidien cancer } \\
\text { with diastatic caecal perforation }\end{array}$ & & 8 & & & 8 \\
\hline Caecal diastatic perforation & & 1 & & & 1 \\
\hline Ileal perforation & & & & 2 & 2 \\
\hline Left colon carcinoma & 2 & & & & 2 \\
\hline $\begin{array}{l}\text { Obstructive left colon carcinoma, with } \\
\text { diastatic caecal perforation }\end{array}$ & & 1 & & & 1 \\
\hline Peritoneal carcinomatosis & 2 & & & & 2 \\
\hline Anastomotic leak & 2 & & & 3 & 5 \\
\hline Acute Appendicitis & & & & & 2 \\
\hline Toxic Megacolon & 2 & 2 & 2 & 3 & 2 \\
\hline Intestinal thrombosis & & & & & 5 \\
\hline Total & 9 & 12 & 2 & 8 & 31 \\
\hline
\end{tabular}

Table 4: Colostomy indications.

\begin{tabular}{|c|c|c|c|c|}
\hline Colostomy Indications & End Colostomy & Loop Colostomy & $\begin{array}{c}\text { Double Barrel } \\
\text { Colostomy }\end{array}$ & Total \\
\hline Recto/sigmoidien cancer (Hartman procedure) & 39 & & & 39 \\
\hline Inferior rectal cancer (Miles procedure) & 8 & 11 & & 19 \\
\hline Perforated sigmoid diverticula (Hartman) & 4 & 1 & & 5 \\
\hline Left colon $\mathrm{Ca}$ & 7 & 1 & 1 & 9 \\
\hline Sigmoid volvulus & 15 & & & 15 \\
\hline Anastomotic leak & 3 & & & 3 \\
\hline
\end{tabular}




\begin{tabular}{|c|c|c|c|c|}
\hline Intestinal fistulas & 2 & & & 2 \\
\hline Aderencial ileus & 1 & & & 1 \\
\hline Parastomal hernias & 1 & & & 1 \\
\hline Rectal perforation from corpus alienum & 4 & & 2 & 6 \\
\hline Peritoneal carcinomatosis & & & 3 & 3 \\
\hline Rectal infiltration from ovarian cancer & 1 & & & 1 \\
\hline Prostate Cancer infiltrating rectum & & 1 & & 1 \\
\hline Rectal stump necrosis & 1 & & & 1 \\
\hline Sphincteral injuries & 4 & & & 4 \\
\hline
\end{tabular}

\section{Gastrostomy/Jejunostomy indications (10 pts)}
A. Gastric ca (carcinomatosis) 3 pts*
B. Esophageal/Cardio-esophageal ca 3 pts
C. Thyroid ca/esophageal fistula $1 \mathrm{pts}$
D. Necrotic-hemorrhagic pancreatitis $1 \mathrm{pt}$
E. Duodenal fistula 2 pts

5.2. Duodenostomy indications (5 pts)
A. Duodenal stump leak 3 pts
B. Duodenal ulcer perforation 2 pts
5.3. Cholecystostomy indications ( 3 pts)

A. Duodenal fistula 2 pts

B. Acute pancreatitis 1pts

*pts-patient

\section{Stoma's early complications (in emergency)}

Though a lifesaving procedure, it may result in significant number of complications. Complications are divided into early complications (up to 30 days after operation) and late complications (more than 30 days after operation. In our study only 17 patients developed complications (Table 5). The most common complication was peristomal skin irritation. Patients with colostomy had more complications than patients with ileostomy

Table 5: Stoma complications.

\begin{tabular}{|c|c|c|c|}
\hline & Ileostomy (4) & Colostomy (13) & Total \\
\hline $\begin{array}{c}\text { Peristomal skin } \\
\text { irritation }\end{array}$ & 3 & 2 & $5(3.2 \%)$ \\
\hline Stoma necrosis & 0 & 3 & $3(1.9 \%)$ \\
\hline Stoma retraction & 0 & 0 & 0 \\
\hline Prolapsed stoma & 0 & 0 & 0 \\
\hline Bleeding & 0 & 2 & $2(1,3 \%)$ \\
\hline $\begin{array}{c}\text { Mucocutaneous } \\
\text { separation }\end{array}$ & 1 & 3 & 4 \\
\hline Stenosis & 0 & 0 & 0 \\
\hline Parastomal hernia & 0 & 1 & $1(0.6 \%)$ \\
\hline Peristomal infections & 0 & 2 & $2(1.3 \%)$ \\
\hline
\end{tabular}

\section{Discussion}

Fecal diversion remains an effective option to treat a variety of gastrointestinal and abdominal conditions [9]. Ileostomy and colostomy are commonly made intestinal stomas in surgery. The first surgical stoma was created more than 200 years ago. The earliest stomas were unintentional ones, enterocutaneous fistulas resulting from penetrating abdominal injuries or complications of intestinal diseases such as incarcerated hernias [10]. A number of patients undergo surgeries for fecal diversion. But despite a great number of such surgeries done, complications are almost inevitable. Patients undergoing stoma formation are at risk of developing a wide range of complications following surgery [11]. There are many factors suggested to predispose to stoma complications like high body mass index, inflammatory bowel diseases, use of steroids and immunosuppressant drugs, diabetes mellitus, old age, emergency surgery, surgical technique and surgeons' experience [12]. The most common stoma made in our study was end colostomy (54\%), followed by loop colostomy (13.5\%) and then by loop ileostomy (6\%). The most common indication for stoma in our study was obstructed rectosigmoid carcinoma. Only 17 patients developed complications, where the most common complication was peristomal skin irritation. A study by Ratliff et al. [13] has shown peristomal irritation in 53\% cases while [14] showed peristomal skin erythema as the most common complication in $42 \%$. Muneer et al. [15] reported skin excoriation in $18 \%$ cases. Safirullah [16] reported skin erythema in $12 \%$ followed by prolapsed (6\%) and retraction (4\%).

\section{Conclusion}

DC principles have been widely applied to the operative management of EGS- emergency general surgery patients. The damage control (DC) laparotomy is therefore not an operation of last resort; rather, it is a well-thought-out stage on a continuum of care which prioritizes the restoration of physiologic normality and homeostasis above definitive organ repair and anatomic reconstruction. Patients with severe sepsis might benefit from damage control surgery (DCS). Initially described for the treatment of major abdominal injuries, indications for DCS have been extended to patients with necrotizing pancreatitis, severe peritonitis, intestinal occlusion or intraperitoneal hemorrhage. The goal of DCS is the same as in trauma surgery: the initial emergency operation is to be kept as short as possible and focused on limiting 
the physiological insult. treatment option depends upon the general condition of the patient, age and contamination of the peritoneal cavity. Fecal/intestinal diversion remains an effective option to treat a variety of gastrointestinal and abdominal conditions. Stoma formation is the best minimum surgical procedure to save the life in emergency intestinal surgery for, obstructive cancer, inflammatory colic disease, anastomotic leaks with low mortality.

\section{References}

1. Taylor P (2005) An introduction to stomas: Reasons for their formation. Nurs Times 101(29): 63-64.

2. Irving MH, Hulme O (1992) Intestinal stomas. Br Med J 304: 1679-1681.

3. Saunders RN, Hemingway D (2005) Intestinal Stomas. SurgInt 71: 44-47.

4. Martin ST, Vogel JD (2012) Intestinal stomas: Indications, management, and complications. Adv Surg 46: 19-49.

5. Renzulli P, Candinas D (2007) Intestinal stomas--indications, stoma types, surgical technique. Ther Umsch 64(9): 517-527.

6. Khalid AM, Irshad W (1991) Surgical history of intestinal obstruction. Specialist 8(1): 55-60.

7. Cushieri A, Steele RJ, Moosa AR (2002) Disorders of the colon and rectum. In: Cushieri A, Steele RJ, Moosa AR (Eds.), Essential Surgical Practice, London, UK, pp. 569-626.
8. Crohn's and Colitis Foundation of America. 386 Park Ave. S. 17thFloor. New York. NY 10016. (800) 826-0826.

9. Abbas MA, Tejirian T (2008) Laparoscopic stoma formation. JSLS 12(2): 159-161.

10. Person OK, Person B, Wexner SD (2005) Complications of construction and closure of temporary loop ileostomy. J Am Coll Surg 201(5): 759773.

11. Grath A, Porrett T, Heyman B (2006) Parastomal hernia: An exploration of the risk factors and the implication. Br J Nurs 15(6): 317-321.

12. Arumugam PJ, Bevan L, Macdonald L, Watkins AJ, Morgan AR, et al. (2003) A prospective audit of stomas-analysis of risk factors and complications and their management. Colorectal Dis 5(1): 49-52.

13. Ratliff, Catherino R (2010) Early Peristomal Skin Complications Reported by WOC Nurses. JWOCN 37(5): 505-510.

14. Pearl RK, Prasad ML, Orsay CP, Abcarian H, Tan AB, et al. (1985) Early local complications from intestinal stomas. Asch Surg 120(10): 11451147.

15. Muneer AA, Shaikh R, Shah GA, Qureshi A (2007) Liaquat university of medical \& health sciences, Jamshoro, Sind Pakistan. World Applied Sciences Journal 2(3): 190-193.

16. Robertson I, Leung E, Hughes D, Splers M, Donnelly L, et al. (2005) Prospective analysis of stoma-related complications. Colorectal Dis 7 (3): 279-285. 